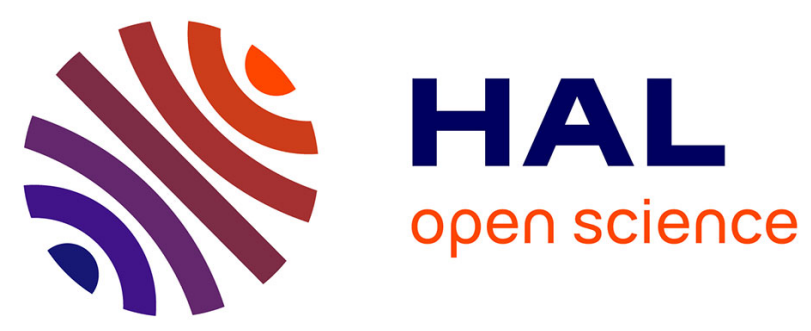

\title{
Li-ion battery pack SoC estimation for electric vehicles
} Kodjo Senou Rodolphe Mawonou, Akram Eddahech, Didier Dumur, Emmanuel Godoy, Dominique Beauvois, Michel Mensler

\section{To cite this version:}

Kodjo Senou Rodolphe Mawonou, Akram Eddahech, Didier Dumur, Emmanuel Godoy, Dominique Beauvois, et al.. Li-ion battery pack SoC estimation for electric vehicles. IECON 2018 - 44th Annual Conference of the IEEE Industrial Electronics Society, Oct 2018, Washington D.C., United States. 10.1109/iecon.2018.8591187 . hal-02111246

\section{HAL Id: hal-02111246}

\section{https://hal-centralesupelec.archives-ouvertes.fr/hal-02111246}

Submitted on 12 Mar 2020

HAL is a multi-disciplinary open access archive for the deposit and dissemination of scientific research documents, whether they are published or not. The documents may come from teaching and research institutions in France or abroad, or from public or private research centers.
L'archive ouverte pluridisciplinaire HAL, est destinée au dépôt et à la diffusion de documents scientifiques de niveau recherche, publiés ou non, émanant des établissements d'enseignement et de recherche français ou étrangers, des laboratoires publics ou privés. 


\section{Li-ion battery pack SoC estimation for electric vehicles}

\author{
Kodjo Senou Rodolphe MAWONOU ${ }^{\mathrm{a}, \mathrm{b}}$ \\ kodjo.mawonou@centralesupelec.fr
}

Emmanuel GODOY ${ }^{a}$

emmanuel.godoy@centralesupelec.fr

\author{
Akram EDDAHECH ${ }^{b}$ \\ akram.eddahech@renault.com
}

Dominique BEAUVOIS ${ }^{a}$

dominique.beauvois@centralesupelec.fr

\author{
Didier DUMUR $^{\text {a }}$ \\ didier.dumur@centralesupelec.fr
}

Michel MENSLER ${ }^{b}$

michel.mensler@ renault.com
${ }^{a}$ Laboratoire des Signaux et Systèmes (L2S, UMR CNRS 8506), CNRS - CentraleSupélec - Université Paris-Sud, Université Paris-Saclay. 3, Rue Joliot Curie, 91192, Gif-sur-Yvette, France.
b Technocentre Renault, 1 Avenue du Golf, 78280 Guyancourt, France.

\begin{abstract}
An accurate state of charge (SoC) estimation by the battery management system (BMS) is crucial for efficient and non-destructive battery-packs operation in electric vehicles (EVs). However, simply replicating an Equivalent Electric Circuit (EEC) method for all cells in a pack leads to huge computational complexity. This paper proposes two different approaches to estimate battery-packs SoC more accurately while keeping a suitable computational burden. We argue that for an operating batterypack, only the limiting cells SoCs and voltages are relevant. The first approach consists of detection of limiting cells based on voltage and current measurement to reduce computational burden. The second is an improvement of the existing "bar-delta" approach developed by Plett. Both of theses approaches lead to significant improvement of limiting cells detection, computational burden reduction and accuracy.

Index Terms-Li-ion battery-pack, Cell variation, EEC model, Dual time-scale, EKF, SoC.
\end{abstract}

\section{INTRODUCTION}

$\mathbf{T}$ HE electrical energy of electric and hybrid vehicles is stored in battery-packs made of numerous electrochemical cells. Lithium-ion cells are the most commonly used, and are one another connected in series and parallel. These battery-packs require an enhanced monitoring performed by a dedicated controller called Battery Management System (BMS) [1]. The BMS is in charge of three types of tasks: Data measurement (current, voltages and temperatures),isolation resistance estimation, various states of the battery estimation and alert elaboration, management of the quantity of usable energy (cells balancing function). Efficient use of the batterypack requires the monitoring of different variables such as: State of charge (SoC), State of health $(\mathrm{SoH})$, the acceptable/available power when charging/discharging, the charge capacity and the internal resistance. Unfortunately these variables are not directly measurable. The BMS has to estimate each of them, thanks to measured data cited above, and state observers [2], [3]. Besides, these parameters change over time and charge-discharge cycles. These changes have to be taken into account by the BMS to insure a maximal level of performance, throughout the life of the battery [4].
Accuracy of estimations provided by the BMS depends on the chosen battery model. Also, the BMS operates on-line leading to limited computational resources. Several models can be found in the literature, such as Equivalent Electric Circuit (EEC) [5]-[7], Electrochemical Model (EM) [8], Fractional Order Model (FOM) [9]-[11] and Neural Network models (NN) [12]. EEC models are the most commonly used and are easy to operate. Electrochemical models are commonly used for design purposes and are not suitable for on-line applications. There were several attempts to simplify these models leading to Single Particle models (SP) [13], [14]. Nevertheless there is no electrochemical operated BMS to our knowledge. It has been argued that solving SP models leads to FOM. Also the impedance frequency response of a Li-ion battery displays at low frequencies behaviours that are easily captured by constant phase elements (CPE). Neural Network models produce satisfying results if enough training data are used. Quite often this approach lacks robustness and requires high computational resources. When dealing with a batterypack, EEC models are the most suitable models to cope both with accuracy and computational issues. There are several approaches in the literature to further reduce the computational burden caused by the number of cells. Plett [15] developed at first the "bar-delta" algorithm that successfully in any batterypack estimates all cell SoC and $\mathrm{SoH}$ values using only slightly more computation than for a single cell. That approach was reused under different names and slight modifications such as "mean + difference" [16]. Wang [11] developed the "mtop/bottom" method consisting in the detection of limiting cells in order to reduce the number of observed cells. The aim of this paper is to propose an enhancement of the " $\mathrm{m}$ top/bottom" and the "bar-delta" methods based on a first order EEC model. This paper is organized as follows. The next section describes the first order EEC model. Section III presents an example of joint $\mathrm{SoC}$ and parameter estimation for this EEC model. A presentation of "m-top/bottom" and "bardelta" methods and their improvement is done in Section IV. Finally conclusions are drawn in Section V. 


\section{Parameter estimation For A Single Cell}

The first order EEC model consists in an ohmic impedance $R_{0}$ in series with a charge transfer impedance $R_{1}$ in derivation with a charge transfer capacity $C_{1}$ as displayed Fig.1. There are two different ways to estimate the parameters of this model. Direct solution: a joint estimation of all parameters or indirect method: estimating $R_{0}$ separately whereas $R_{1}$ and $C_{1}$ are estimated jointly.

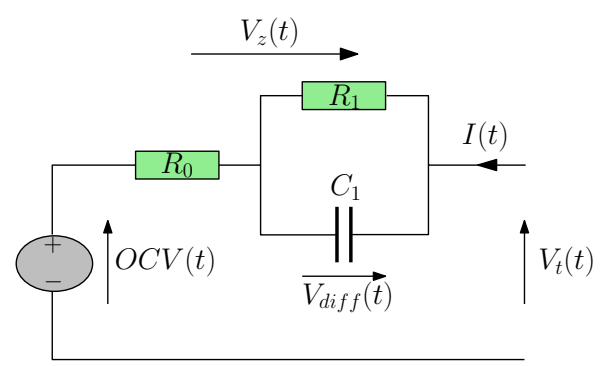

Fig. 1. First order EEC model. $V_{t}$ and $I$ are measured.

\section{A. Indirect method: $R_{0}$ separately}

The ohmic impedance can be estimated using the battery current and voltage at some specific moments. Considering the EEC model, the ohmic impedance can be computed subsequently to a small pause followed by a current pulse excitation. These small pauses of up to $30 \mathrm{~s}$ often occur in traffic. $R_{0}$ can then be computed using equation 1 .

$$
R_{0}=\frac{V_{t}[k]-V_{t}[k-1]}{I[k]-I[k-1]}
$$

It is one simple way to estimate the battery ohmic resistance. Once the ohmic impedance is estimated, the remaining voltage $V_{\text {diff }}$ can be used to estimate charge transfer phenomenon. Considering the first order EEC model, one can write the following transfer:

$$
\frac{V_{\text {diff }}(s)}{I(s)}=\frac{R_{1}}{1+R_{1} C_{1} s}
$$

Parameters $R_{1}$ and $C_{1}$ can be easily estimated using an Adaptive Recursive Least Square (RLS) algorithm with parameters $\Theta=\left[\begin{array}{lll}R_{1} & R_{1} C_{1}\end{array}\right]$ and measurements $\Phi=\left[\begin{array}{ll}I_{k} & V_{\text {diff }, k-1}\end{array}\right]^{T}$.

\section{B. Direct method: $R_{0}+R_{1} / / C_{1}$ jointly}

The straightforward approach is to estimate simultaneously the three parameters $R_{0}, R_{1}$ and $C_{1}$. The transfer between the voltage and the current can then be written as follows:

$$
\begin{gathered}
\frac{V_{z}(z)}{I(z)}=\frac{\alpha_{0}+\alpha_{1} z^{-1}}{1-\beta z^{-1}} \\
\left\{\begin{array}{l}
\alpha_{0}=R_{0}+R_{1} \frac{T_{s}}{T_{s}+\tau_{1}} \\
\alpha_{1}=-R_{0} \frac{\tau_{1}}{T_{s}+\tau_{1}} \\
\beta=\frac{\tau_{1}}{T_{s}+\tau_{1}} \\
\tau_{1}=R_{1} C_{1}
\end{array}\right.
\end{gathered}
$$

with parameters from equation 4 with the sampling time $T_{s}=100 \mathrm{~ms}$. Using an adaptive RLS algorithm one can estimate parameters $\Theta=\left[\begin{array}{lll}\alpha_{0} & \alpha_{1} & \beta\end{array}\right]$ with measurements $\Phi=\left[\begin{array}{llll}I_{k} & I_{k-1} & V_{z, k-1}\end{array}\right]^{T}$.

\section{Cell SoC estimation based on Kalman FILTERING}

Using equation 5 jointly with the parameter estimator described in section II, one can estimate the SoC of the Li-ion cell as displayed Fig.2. It is a dual estimator scheme with an RLS component that estimates the EEC model parameters using measured currents $I_{k}, I_{k-1}$ and the estimated state of charge $S o C_{k-1}$. A convergence test is run to retrieve converged parameters $R_{0, c o n v}, R_{1, \text { conv }}$ and $C_{1, \text { conv }}$. These converged parameters are then used by the EKF observer to estimate the states: $\left[S o C_{k} V_{d i f f, k}\right]^{T}$.

$$
\left\{\begin{array}{l}
\left(\begin{array}{c}
S o C_{k} \\
V_{d i f f, k}
\end{array}\right)=A\left(\begin{array}{c}
S o C_{k-1} \\
V_{d i f f, k-1}
\end{array}\right)+B I_{k} \\
V_{t, k}=O C V\left(S o C_{k}\right)+V_{d i f f, k}+R_{0} I_{k}
\end{array}\right.
$$

Where $A=\left[\begin{array}{cc}1 & 0 \\ 0 & e^{-\frac{T_{s}}{R_{1} C_{1}}}\end{array}\right], B=\left[\begin{array}{c}\frac{\eta_{f} T_{s}}{Q_{c e l l}} \\ R_{1}\left(1-e^{-\frac{T_{s}}{R_{1} C_{1}}}\right)\end{array}\right], \eta_{f}$ the Faraday efficiency and $Q_{\text {cell }}$ the charge capacity. The function $O C V(S o C)$ is an optimized lookup table provided by the manufacturer of the Li-ion batteries used in this paper.

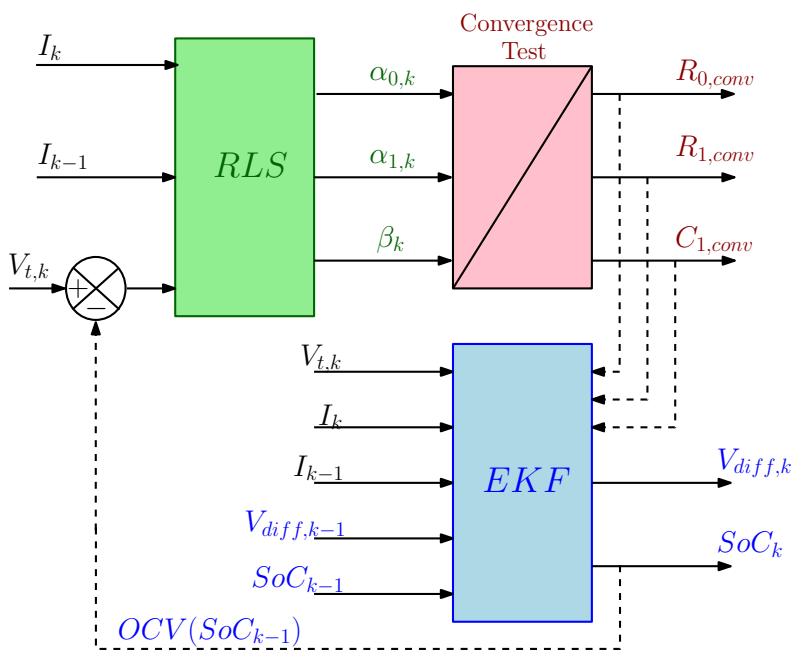

Fig. 2. SoC estimation.

Using this scheme and data recorded from a Li-ion cell during highway driving cycle at $25^{\circ} \mathrm{C}$, both $\mathrm{SoC}$ and parameters of the first order EEC model were estimated for a Li-ion cell. Fig. 3 displays the input current whereas Fig. 4 displays the output voltage. The estimated parameters are displayed on Fig.5. Ohmic impedance $R_{0}$ is displayed using blue solid line, charge transfer impedance $R_{1}$ is displayed using dotted blue line and finally, time constant $\tau_{1}$ is displayed using the red dotted line, whereas the estimated state of charge and the estimation error are displayed on Fig.6. The maximum SoC estimation error is $2 \%$. 


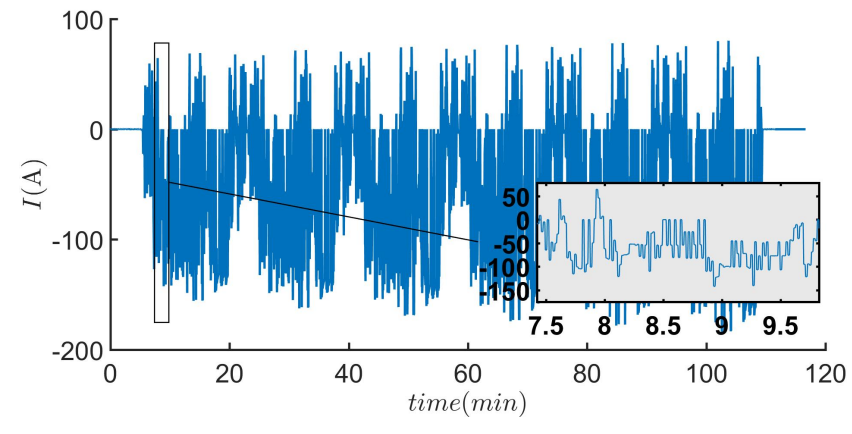

Fig. 3. Highway driving cycle input current at $25^{\circ} \mathrm{C}$

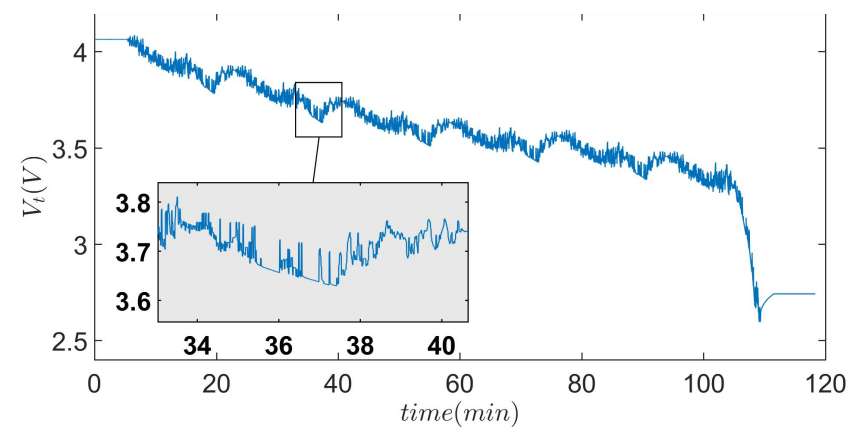

Fig. 4. Highway driving cycle output voltage at $25^{\circ} \mathrm{C}$. (Experimental data)

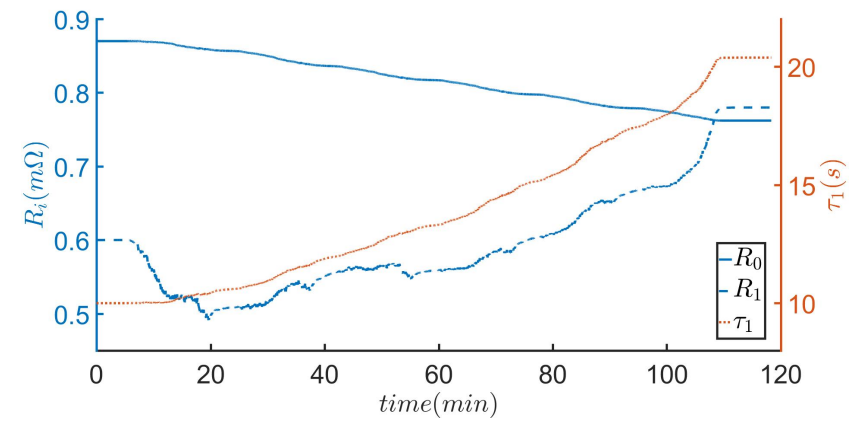

Fig. 5. Parameters: Ohmic impedance $R_{0}$ (blue solid line), charge transfer impedance $R_{1}$ (dotted blue line) and time constant $\tau_{1}$ (red dotted line).

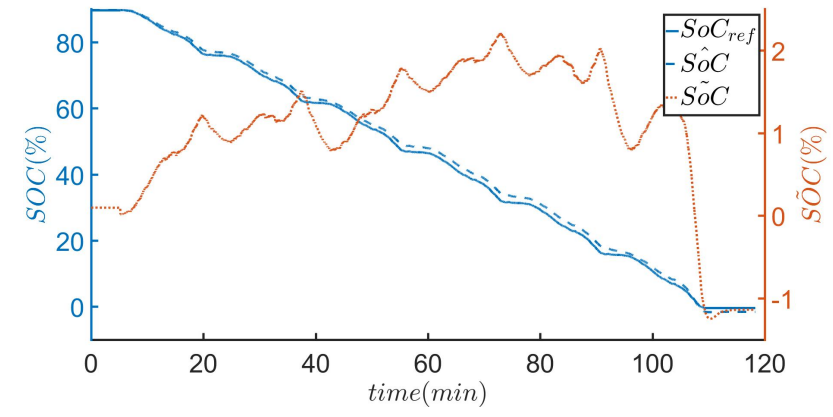

Fig. 6. State of charge: Reference $S o C_{r e f}$ (blue solid line), estimated $\hat{S o C}$ (dotted blue line) and the error $S \tilde{S} C$ (red dotted line).

\section{BATTERY-PACK SOC ESTIMATION}

During charge/discharge, there are upper/lower bounds for the terminal voltage and SoC for each cell in the battery-pack. For example, when discharging the battery, there is a limit voltage not to be reached $\left(V_{t, \min }=2.8 \mathrm{~V}\right)$. Also, the final user is only interested in the $\mathrm{SoC}$ of the pack. It has been argued by Plett [15] that the best way to monitor the SoC of a batterypack is to estimate the SoC of the less/most charged cell during discharge/charge. In fact, considering 3 cells connected in series where $S o C_{1}=98 \%, S o C_{2}=47 \%$ and $S o C_{3}=2 \%$ as displayed Fig.7, it is obvious that we can not assume that the global $S o C$ is the average one $49 \%$. But it is crucial to be aware that Charging process should stop as soon as $\mathrm{Cell}_{1}$ has acquired $2 \%$ charge. Similarly, discharging process should stop as soon as $\mathrm{Cell}_{3}$ reaches $V_{t, \text { min }}$ or $S o C_{m i n}$. Therefore,
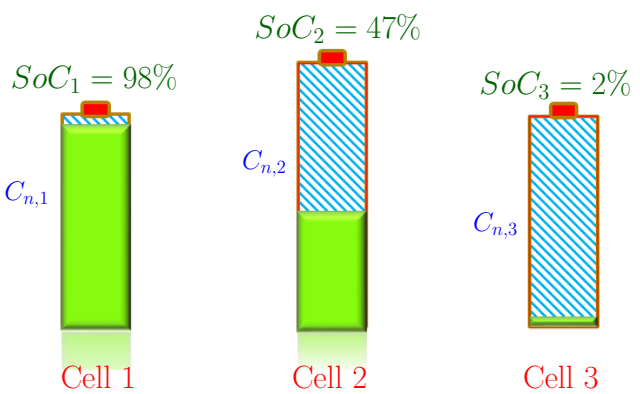

Fig. 7. SoC of 3 cells connected in series

it is mandatory to detect and monitor at least the limiting cells in charge/discharge or find a faster way to compute the SoC of all the battery cells.

\section{A. Limiting cells detection}

It is often assumed that the cell with the lowest voltage is more likely to have the lowest SoC [17], [18]. That assumption is not always true especially if there is a significant discrepancy among internal impedances inside the battery-pack, which often happens subsequently to ageing. "M-top/bottom" is an attempt by Wang [19] to cope with the detection of the cell presenting the lowest/highest SOC. The idea is to select the $m$ lowest (bottom) voltage cells and estimate their SoC. The lowest $\mathrm{SoC}$ in the pack is assumed to be the lowest SoC among the $m$ selected cells. The same argument applies for the $m$ highest (top) voltages, leading to the name "m-top/bottom". This method produces satisfying results as $m$ tends to the total number of cells in the pack. The drawback is the increase of computational burden as the value of $m$ increases. In this paper, we propose an enhancement of this method. Given that there is a direct relation between the SoC and the OCV of each Li-ion cell, we try to approach the value of the OCV by subtracting the ohmic resistance component from the terminal voltage using equation 6 .

$$
O \hat{C} V-V_{\text {diff }}=V_{t}-R_{0} I
$$


To estimate the ohmic resistance $R_{0}$, we use the equation 1 from section II. $R_{0}$ value is estimated after small pauses of $30 \mathrm{~s}$ that occur in traffic. We then base our choice on the approximate value of the Open Circuit Voltage : $V_{t}-R_{0} I$, assuming a small discrepancy among $V_{\text {diff }}$ values. In fact, fast dynamics of urban driving cycles input currents only slightly trigger diffusion components of the battery. We define the success rate as the ratio between the number of times the actual limiting cell belongs to the $m$ selected cells and the total number of measurements. We ran the test for a batterypack under urban driving cycle current input at $25^{\circ} \mathrm{C}$ and $0^{\circ} \mathrm{C}$. Using this approach leads to a significant improvement of the limiting cells detection. This method is a major improvement compared to the straightforward method. Even with $m=2$, the success rate improvement is approximately $10 \%$ with almost $90 \%$ chance to successfully detect the limiting cell as laid down in Table I. On Fig.8 is displayed the success rate improvement obtained using this new method at $0^{\circ} \mathrm{C}$ and $25^{\circ} \mathrm{C}$ instead of the original one. Similar results improvement are obtained for both temperature conditions. Unfortunately for this approach only the $m$ selected cells are monitored. To go further, the next approach will be about reducing the computational burden while monitoring all the cells in the battery-pack.

\begin{tabular}{|c||c||c||c||c|}
\hline$m$ & $\begin{array}{c}V_{t, \max }[\%] \\
{\left[\%, \hat{R}_{0} I\right)_{\max }} \\
{[\%]}\end{array}$ & $\begin{array}{c}\left(V_{t}-\hat{R}_{0} I\right)_{\min } \\
{[\%]}\end{array}$ \\
\hline 1 & 47,76 & 52,74 & 63,83 & 62,64 \\
\hline 2 & 74,39 & 78,44 & 90,71 & 88,79 \\
\hline 4 & 84,60 & 94,50 & 95,39 & 97,81 \\
\hline 8 & 89,90 & 99,58 & 100 & 98,7 \\
\hline 12 & 92,08 & 100 & 100 & 98,7 \\
\hline
\end{tabular}

TABLE I

SUCCESS RATE COMPARISON BETWEEN THE STRAIGHTFORWARD AND THE IMPROVED "M-TOP/BOTTOM" METHOD APPLIED TO A 96-CELLS PACK UNDER AN URBAN DRIVING CYCLE CURRENT INPUT AT $25^{\circ} \mathrm{C}$.

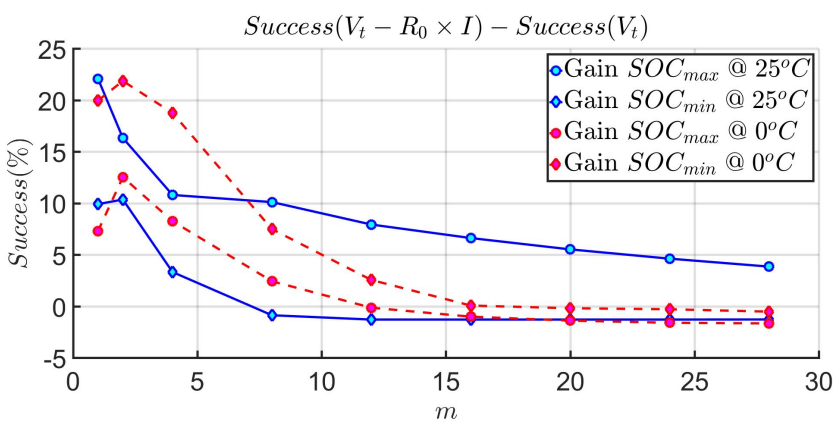

Fig. 8. Improvement results of the m-top/bottom method for 96 cells pack under urban driving cycle input current at $25^{\circ} \mathrm{C}$ and $0^{\circ} \mathrm{C}$ temperature. (Using experimental data)

\section{B. Modified Bar-Delta algorithm}

1) Introduction to "bar-delta" algorithm: The Bar-Delta algorithm was introduced back in 2009 by G. L. Plett [15], [20]. He argued that pack SoC does not make any sense but limiting SoC does. To that extent it is mandatory to estimate $S o C$ for all the in-pack cells. To alleviate the computational burden, he introduced the the concept of an "average cell" capturing fast dynamics in a cell. He then argued that the states of each cell can be viewed as the sum of the states of the average cell and a slight variation, presenting with slow dynamics, intrinsic to each cell using equation 7 , where $\bar{x}_{k}$ is the pack-average state vector and $\Delta x_{k}^{(i)}$ is the difference between the state vector of cell $i$ and the pack average state vector. Variable $\bar{x}_{k}$ is called " $x$-bar" and $\Delta x_{k}^{(i)}$ is called "delta$x$ " leading to the name "Bar-Delta".

$$
x_{k}^{(i)}=\bar{x}_{k}+\Delta x_{k}^{(i)}
$$

a) The bar-filter: The voltage of the average cell is computed as : $\bar{V}_{t}=\frac{1}{N} \sum_{i=1}^{N} V_{t, i}$. Using EEC model as in section III, a Kalman filter is designed to estimate $\bar{x}_{k}=$ $\left[\begin{array}{ll}S \bar{o} C_{k} & \bar{V}_{d i f f, k}\end{array}\right]^{T}$ by replacing $R_{0}$ with $\bar{R}_{0}$, one can easily operate the "bar-filter".

b) The delta-filters: For the $i$-th cell, one can write the "delta-SoC" estimator from equation 8 noting $S_{o} C_{k}=\bar{z}_{k}$, $S o C_{k}^{(i)}=z_{k}^{(i)}$ and $\Delta S o C_{k}^{(i)}=\Delta z_{k}^{(i)}$, where $\nu_{k}$ is the terminal voltage measurement noise (supposed white and centred).

$$
\left\{\begin{array}{l}
\Delta z_{k}^{(i)}=\Delta z_{k-1}^{(i)}+I_{k-1} T_{s} \Delta Q_{i n v, k-1}^{(i)} \\
V_{t, k}^{(i)}=O C V\left(\bar{z}_{k}+\Delta z_{k}^{(i)}\right)+R_{0, k}^{(i)} I_{k}+\bar{V}_{d i f f, k}+\nu_{k}
\end{array}\right.
$$

Noting $Q_{i n v}=1 / Q$, the capacity variation $\Delta Q_{i n v, k}^{(i)}$ is estimated using equation 9, with $d_{k}$ is a zero mean residual signal induced by the evolution of the state of charge, $e_{k}$ is SoC measurement noise (supposed white and centred), $n_{k}^{\Delta Q_{i n v}}$ is the state noise (supposed white and centred) and $Q_{i n v}^{(i)}=\bar{Q}_{i n v, k-1}+\Delta Q_{i n v, k-1}^{(i)}$.

$$
\begin{cases}\Delta Q_{i n v, k}^{(i)} & =\Delta Q_{i n v, k-1}^{(i)}+n_{k}^{\Delta Q_{i n v}} \\ d_{k} & =z_{k-1}^{(i)}-z_{k}^{(i)}+I_{k-1} T_{s} Q_{i n v, k-1}^{(i)}+e_{k}\end{cases}
$$

Similarly one can operate the ohmic resistance estimation using equation 10 , where $\nu_{k}^{\Delta R_{0}}$ is the terminal voltage measurement noise (supposed white and centred) and replacing $R_{0, k}^{(i)}=\bar{R}_{0, k}+\Delta R_{0, k}^{(i)}$.

$$
\left\{\begin{array}{l}
\Delta R_{0, k}^{(i)}=\Delta R_{0, k-1}^{(i)}+n_{k}^{\Delta R_{0}} \\
V_{t, k}^{(i)}=\operatorname{OCV}\left(z_{k}^{(i)}\right)+R_{0, k}^{(i)} I_{k}+\bar{V}_{d i f f, k}+\nu_{k}^{\Delta R_{0}}
\end{array}\right.
$$

This approach has been used under different assumptions in references [16], [21]-[24] and lately in [25]. Plett concluded that for a pack of $N$ cells, if at each sample time only one "delta-filter" and the "bar-filter" are updated, the overall computational time is divided by $n=N / 2$ in comparison to updating $N$ complete filters. This means that the "bar-filter" is updated every $T_{s}$ whereas the "delta-filters" are updated sequentially each $N \times T_{s}$ ( $N$ cells in the pack). Furthermore, Plett argued that the "delta-filters" run even faster than the "bar-filter" because they are one-state filters. Therefore they are less complex than the "bar-filter", which suggests that $N / 2 \leq n<N$ 
We have applied this approach to a battery-pack of $N=96$ cells to estimate $\Delta z^{i}$ and $\Delta R_{0}^{i}$. The estimated values of $\Delta z^{i}$ and $\Delta R_{0}^{i}$ from the "delta-filters" are displayed on Fig.9. One can see that those values vary very slowly knowing that for this test the $S o C$ went from $93 \%$ to $0 \%$ as displayed Fig. 10 a). This assesses the assumption made by Plett when he coined this method.
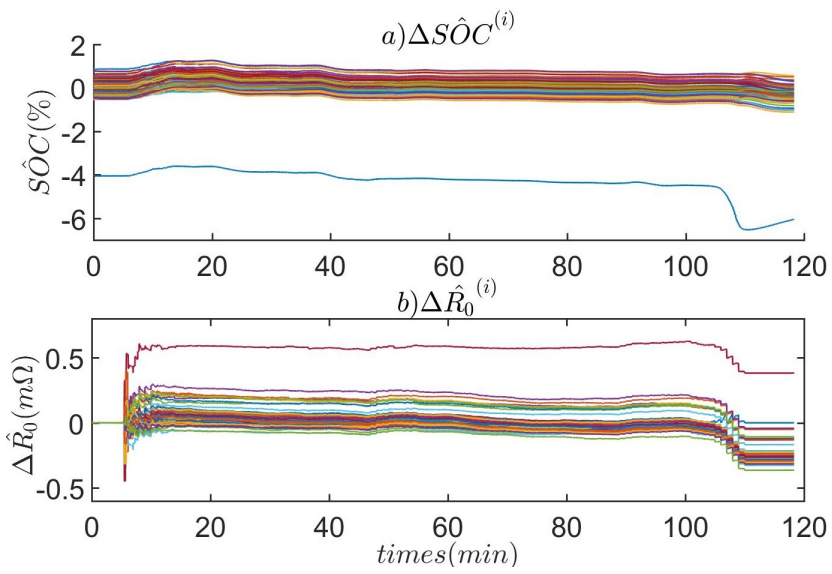

Fig. 9. a) Estimated $\Delta z^{i}$ b) Estimated $\Delta R_{0}^{i}$, for a 96 Li-ion cells pack $\left(\mathrm{EV}: Q_{n}=128 \mathrm{Ah}\right.$ ) under highway driving cycle, at $25^{\circ} \mathrm{C}$. (Updated each $N \times T_{s}=9.6 s$, using experimental data)
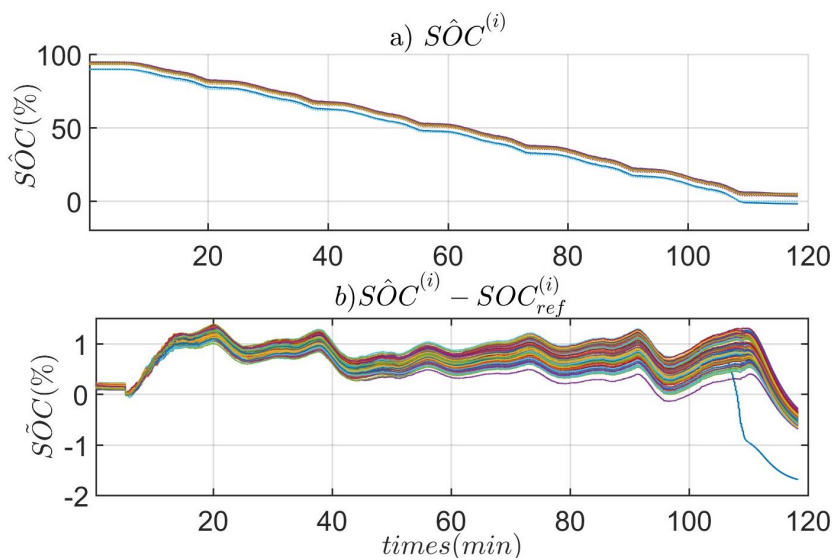

Fig. 10. a) Estimated $S o C^{(i)}$ b) Estimation errors $S \tilde{o} C^{(i)}=S o C^{(i)}-$ $S o C_{r e f}^{(i)}$, for a $96 \mathrm{Li}$-ion cells pack $\left(\mathrm{EV}: Q_{n}=128 \mathrm{Ah}\right)$ under highway driving cycle, at $25^{\circ} \mathrm{C}$. (Updated each $T_{s}=0.1 \mathrm{~s}$, using experimental data)

As suggested earlier, the computational time should be divided by a number $n$ such that $N / 2=48 \leq n<N=96$. To assess that assumption, we ran the algorithm for a number of cells $N$ ranging from 10 to 96 . We then divided the computational time required for the straightforward $N$-EKF to the one obtained using "Bar-Delta" algorithm. The time gain ratio is displayed on Fig.11. We have run the test for two different kinds of vehicles : Plug-in Hybrid (PHEV) and EV (EV). Using data from Fig. 11 we found that the computational time was divided by $N / 1.23$ for Plug-in Hybrid vehicles (PHEV), and $N / 1.32$ for electric vehicles (EV).

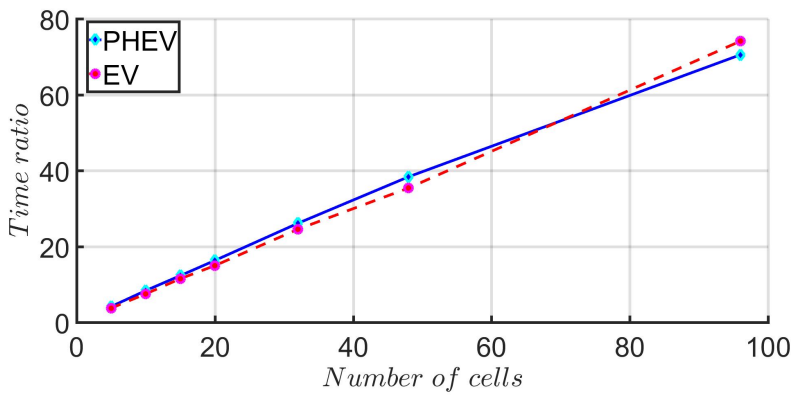

Fig. 11. Computational time improvement using "Bar-Delta" method. Test ran for two different kinds of vehicles : Plug-in Hybrid (PHEV) and EV (EV).

2) Improvement of the "bar-delta" algorithm: Having successfully implemented the "Bar-Delta" approach for EV and PHEV battery-packs and observed the computation time gains it provided, we met our first goal which is a faster algorithm. The slow varying differences $\left(\Delta x^{(i)}\right)$ allows us to compute them less often, which leads to computation time gain. Our second goal to meet is a more accurate pack-SoC estimation. Given that the $\mathrm{SoC}$ of the limiting cell is the most critical, we have decided to modify the "bar-delta" algorithm considering the limiting cell in the "bar-filter" instead of a virtual average cell. At high SoCs $(>66 \%)$, the nominal cell would be the most charged one. The same argument works for the less charged cell at low SoCs $(<33 \%)$ hence Fig.12. The

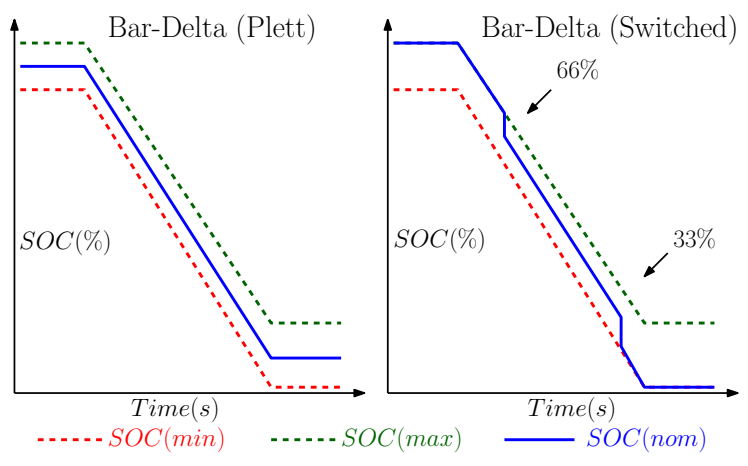

Fig. 12. Bar-Delta Vs Bar-Delta Switched.

idea behind the switch is that for the classical approach, the assumptions of a slow varying differences $\left(\Delta x^{(i)}\right)$ does not hold if the nominal (average for Plett) capacity $\bar{Q}$ is small or a specific cell in the pack discharges significantly faster than all the other cells. If this kind of cell ever happens to be the limiting cell, our goal is to capture its behaviour as accurately and as quickly as possible. To test our assumption, we have considered a simulated Li-ion battery-pack of 96 cells. The nominal cell charge capacity is $Q_{\text {nom }}=10 \mathrm{Ah}$. We then considered $10 \%$ capacity discrepancy within the pack, to simulate an aged pack. We ran our improved algorithm for this simulated battery-pack under an urban driving cycle at $25^{\circ} \mathrm{C}$. On Fig. 13 we have displayed the SoC error for its minimum and maximum values. Our switched method leads 
to an estimation error close to $0 \%$ at the end of the test for $S o C_{\min }$ estimation. Unfortunately, the drawback is a higher $S o C_{\max }$ estimation error. But, as it was a discharge mode, we are more focused on relevant $S o C_{\min }$ estimate for low SoC conditions $(<33 \%)$. Also in that domain, only the minimum SoC is relevant. Therefore the higher error for maximum available SoC estimation is not a concern.

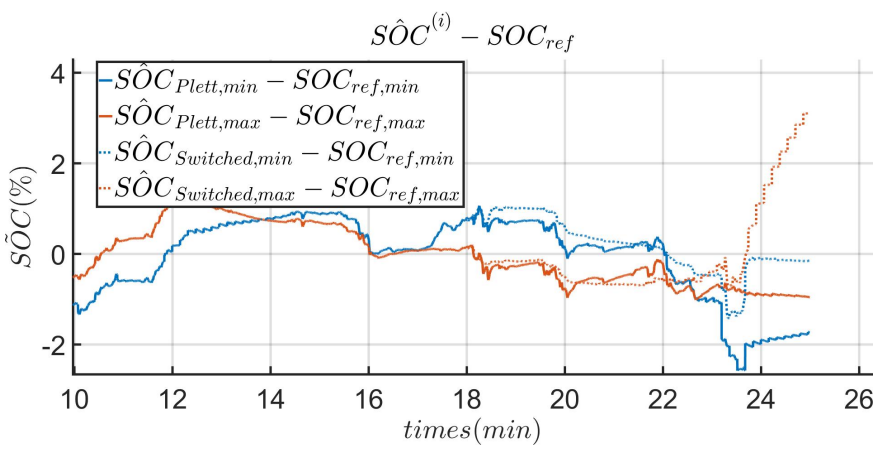

Fig. 13. Errors on minimum and maximum Pack SoC estimation comparison between "Bar-Delta" and "Bar-Delta Switched" algorithms.(Using simulated cells)

\section{CONCLUSION}

In this paper we presented two simple methods to estimate first order EEC model parameters for Li-ion batteries. We then introduced a joint estimator for parameters $R_{0}, R_{1}$, $\tau_{1}$ and the state of charge $S o C$. We also presented two different approaches to handle battery-pack SoC estimation. As discussed it is mandatory to either detect the limiting cells or estimate the SoC of every cell in the pack. We presented "m-top/bottom" method for limiting cells detection and "bardelta" method for fast estimation of all cells in the pack SoC. We also provided improvement for each of these approaches leading to the modified "m-top/bottom" and the switched "bar-delta" methods. The modified "m-top/bottom" method leads to a more accurate detection of limiting cells, while the switched "bar-delta" method improves the accuracy of the SoC estimation at low charge. To go further, more accurate models of Li-ion batteries such as: electrochemical models or fractional order models will be considered in our future works.

\section{REFERENCES}

[1] L. Guzzella and A. Sciarretta, Vehicle Propulsion Systems: Introduction to Modeling and Optimization, 012007.

[2] G. Plett, "Method and system for joint battery state and parameter estimation," Patent US 7,593,821, 2009.

[3] G. L. Plett, "System and method for estimating a state vector associated with a battery," Patent US 7,800,375, 2010.

[4] W. Waag, "Adaptive algorithms for monitoring of lithium-ion batteries in electric vehicles," Ph.D. dissertation, Jul. 2014

[5] G. L. Plett, "Extended Kalman filtering for battery management systems of LiPB-based HEV battery packs: Part 1. Background," Journal of Power Sources, vol. 134, no. 2, pp. 252-261, Aug. 2004.

[6] G. Plett, "Extended Kalman filtering for battery management systems of LiPB-based HEV battery packs: Part 2. Modeling and identification," Journal of Power Sources, vol. 134, no. 2, pp. 262-276, Aug. 2004.
[7] G. L. Plett, "Extended Kalman filtering for battery management systems of LiPB-based HEV battery packs: Part 3. State and parameter estimation," Journal of Power Sources, vol. 134, no. 2, pp. 277-292, Aug. 2004.

[8] C. M. Doyle, "Design and Simulation of Lithium Rechargeable Batteries," Ph.D. dissertation, University of California, Aug. 1995.

[9] J. Sabatier, J. M. Francisco, F. Guillemard, L. Lavigne, M. Moze, and M. Merveillaut, "Lithium-ion batteries modeling: A simple fractional differentiation based model and its associated parameters estimation method," Signal Processing, vol. 107, pp. 290-301, Feb. 2015.

[10] X. Li, G. Fan, K. Pan, G. Wei, C. Zhu, G. Rizzoni, and M. Canova, "A physics-based fractional order model and state of energy estimation for lithium ion batteries. Part I: Model development and observability analysis," Journal of Power Sources, vol. 367, pp. 187-201, Nov. 2017.

[11] B. Wang, Z. Liu, S. E. Li, S. J. Moura, and H. Peng, "State-of-Charge Estimation for Lithium-Ion Batteries Based on a Nonlinear Fractional Model," IEEE Transactions on Control Systems Technology, vol. 25, no. 1, pp. 3-11, Jan. 2017.

[12] S. R. Bhatikar, R. L. Mahajan, K. Wipke, and V. Johnson, "Artificial Neural Network Based Energy Storage System Modeling for Hybrid Electric Vehicles," SAE International, Warrendale, PA, SAE Technical Paper 2000-01-1564, Apr. 2000, dOI: 10.4271/2000-01-1564.

[13] A. Bizeray, S. Duncan, and D. Howey, "Advanced battery management systems using fast electrochemical modelling," in IET Hybrid and Electric Vehicles Conference 2013 (HEVC 2013), Nov. 2013, pp. 1-6.

[14] N. A. Chaturvedi, R. Klein, J. Christensen, J. Ahmed, and A. Kojic, "Algorithms for Advanced Battery-Management Systems," IEEE Control Systems, vol. 30, no. 3, pp. 49-68, Jun. 2010.

[15] G. L. Plett, "Efficient Battery Pack State Estimation using Bar-Delta Filtering," Apr. 2009.

[16] Y. Zheng, M. Ouyang, L. Lu, J. Li, X. Han, L. Xu, H. Ma, T. A. Dollmeyer, and V. Freyermuth, "Cell state-of-charge inconsistency estimation for LiFePO4 battery pack in hybrid electric vehicles using meandifference model," Applied Energy, vol. 111, no. Supplement C, pp. 571-580, Nov. 2013.

[17] X. Liu, Y. He, and Z. Chen, "State-of-Charge estimation for power Liion battery pack using Vmin-EKF," in The 2nd International Conference on Software Engineering and Data Mining, Jun. 2010, pp. 27-31.

[18] C. Truchot, M. Dubarry, and B. Y. Liaw, "State-of-charge estimation and uncertainty for lithium-ion battery strings," Applied Energy, vol. 119, pp. 218-227, Apr. 2014

[19] W. Wang, P. Malysz, D. Wang, R. Gu, H. Yang, and A. Emadi, "Efficient multi-cell SOC estimation for electrified vehicle battery packs," Jun. 2016, pp. 1-5.

[20] G. Plett, "System, methode, and article of manufacture for determining an estimated battery cell module state," Patent US 8519675 B2, 08 27, 2013.

[21] M. A. Roscher, O. S. Bohlen, and D. U. Sauer, "Reliable State Estimation of Multicell Lithium-Ion Battery Systems," IEEE Transactions on Energy Conversion, vol. 26, no. 3, pp. 737-743, Sep. 2011.

[22] H. Dai, X. Wei, Z. Sun, J. Wang, and W. Gu, "Online cell SOC estimation of Li-ion battery packs using a dual time-scale Kalman filtering for EV applications," Applied Energy, vol. 95, no. Supplement C, pp. 227-237, Jul. 2012.

[23] F. Sun and R. Xiong, "A novel dual-scale cell state-of-charge estimation approach for series-connected battery pack used in electric vehicles," Journal of Power Sources, vol. 274, no. Supplement C, pp. 582-594, Jan. 2015

[24] F. Sun, R. Xiong, and H. He, "A systematic state-of-charge estimation framework for multi-cell battery pack in electric vehicles using bias correction technique," Applied Energy, vol. 162, pp. 1399-1409, Jan. 2016.

[25] J. Wei, G. Dong, Z. Chen, and Y. Kang, "System state estimation and optimal energy control framework for multicell lithium-ion battery system," Applied Energy, vol. 187, pp. 37-49, Feb. 2017. 